\title{
SISTEMAS DE BÚSQUEDA Y VISUALIZACIÓN EN BANCOS DE IMÁGENES COMERCIALES
}

\author{
Luisa Perdices-Castillo y Antonio Perianes-Rodríguez
}
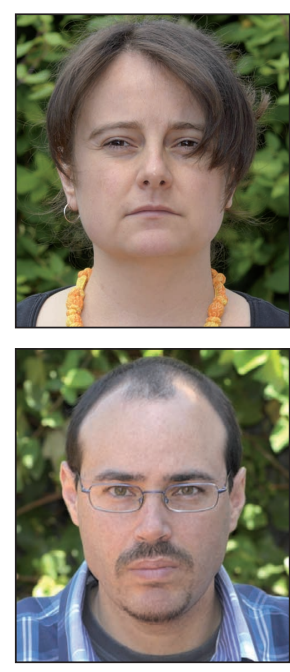

Luisa Perdices-Castillo es diplomada en biblioteconomía y documentación por la Universidad Carlos III de Madrid y licenciada en documentación por la Universidad de Alcalá de Henares. Ha trabajado como responsable de equipo en diversas empresas tecnológicas durante los últimos quince años. Es consultora y asesora de información digital de Alfaquí Fotografía.

Alfaquí Fotografía Fermín Caballero, 64 - 4C. 28034 Madrid marisa@alfaqui.com http://www.alfaqui.com

Antonio Perianes-Rodríguez es profesor ayudante doctor en el Departamento de Biblioteconomía y Documentación de la Universidad Carlos III de Madrid e investigador del grupo SCImago.

Universidad Carlos III de Madrid Dpto. Biblioteconomía y Documentación Madrid, 128. 28903 Getafe (Madrid) antonio.perianes@uc3m.es ttp://www.scimago.es/perianes/welcome.htm

\section{Resumen}

La aparición de internet, la irrupción de la fotografía digital y la posibilidad de digitalizar grandes volúmenes de imágenes ha revolucionado el sector de los bancos de imágenes comerciales. El paso al formato digital ha supuesto un cambio sustancial en el proceso de trabajo, pasando a disponer de una gran oferta de imágenes en línea. Se muestra el perfil y las características básicas que cualquier banco de imágenes comercial debe ofrecer a sus clientes en cuestiones como la recuperación, visualización en pantalla y descarga para diversos fines editoriales.

\section{Palabras clave}

Bancos de imágenes, Fotografía digital, Agencias de fotografía, Bases de datos de imágenes, Recuperación y almacenamiento de información en línea.

Title: Image retrieval and visualization systems in stock photography agencies

\begin{abstract}
The advent of the internet, the impact of digital photography and the ability to scan large volumes of images has revolutionized the stock photography agencies. The transformation from analogue to digital photography has involved a substantial change in daily work processes, providing a large number of images online. The present work will reveal the profile and the basic features that any stock photography agency must offer on issues such as image retrieval, on-screen visualization, and storage for many diverse editorial activities.
\end{abstract}

\section{Keywords}

Stock photography, Digital photography, Photography agencies, Image databases, Online information storage and retrieval.

Perdices-Castillo, Luisa; Perianes-Rodríguez, Antonio. "Sistemas de búsqueda y visualización en bancos de imágenes comerciales". El profesional de la información, 2011, julio-agosto, v. 20, n. 4, pp. 439-443.

\section{Introducción}

La aparición de internet y la generalización de su uso (Web, correo electrónico, ftp), la irrupción de la fotografía digital y la posibilidad de digitalizar grandes volúmenes de foto-

Artículo recibido el 28-04-11

Aceptación definitiva: 25-05-11 grafías, negativos, diapositivas o daguerrotipos ha revolucionado el sector de los bancos de imágenes comerciales y ha cambiado la forma de trabajo, tanto desde el punto de vista del usuario que necesita y busca imágenes (editoriales, revistas, periódicos, agencias de publicidad o televisiones), 
como desde el punto de vista de la prestación de ese servicio por parte de las agencias e intermediarios involucrados y de los propios fotógrafos que nutren con sus producciones dichos bancos de imágenes.

A finales de los 90 los directores de arte y editores gráficos de los medios de comunicación, ante la necesidad de una imagen, contactaban con un reducido número de agencias para sondear sus fondos y conseguir una selección de no más de 10 diapositivas. Una vez elegida la imagen, y tras negociar los derechos para su uso, debían devolver el resto (Levine, 2007). Esto obligaba a las agencias a tener siempre disponibles varias copias del mismo material ante la posibilidad de contar con peticiones simultáneas, con el consiguiente esfuerzo de seguimiento y control de los envíos y devoluciones, y dependiendo de empresas de mensajería para realizar las entregas con plazos de tiempo muy ajustados. En un breve lapso de tiempo, el paso a lo digital trajo consigo un cambio sustancial en el proceso de trabajo, pasando a disponer de un gran número de agencias con una enorme oferta de imágenes en línea, disponibles en alta resolución mediante una sencilla descarga, y listas para su impresión, edición o maquetación en un par de clics.

Este entorno digital obligó a los bancos de imágenes a adaptarse a marchas forzadas digitalizando colecciones completas, creando sitios web, empleando motores de búsqueda y entornos de trabajo fáciles y amigables para sus usuarios, y modernizando los sistemas de gestión de derechos (Levine, 2007). En el proceso muchas pequeñas agencias desaparecieron (y siguen haciéndolo) absorbidas por aquellas que disponen de medios suficientes para comprar colecciones completas, añadiéndolas a las propias, y elaborar herramientas ad hoc adaptadas a las necesidades del nuevo mercado. Al mismo tiempo, otras muchas nacen o se mantienen utilizando y adaptando programas especializados de gestión de imágenes (FotoWeb, 2011; Infradox, 2011; Orphea Studio, 2011), y ofreciendo especialización temática como signo distintivo frente a las grandes agencias generalistas.

En cualquier caso, e independientemente de la importancia o del tamaño del banco de imágenes, existe una serie de aspectos técnicos esenciales que cualquiera de estos productos debe ofrecer a la hora de realizar las búsquedas, presentar los resultados y descargar los archivos.

Los bancos de imágenes se encuentran en la vanguardia de las herramientas de búsqueda de información

\section{Objetivo y justificación}

Aunque en el mercado hay cada vez mayor competencia, son dos los bancos de imágenes que copan el panorama internacional, Corbis y Getty (Levine, 2007; Piclet, 2011). Son los más importantes tanto por el volumen de sus fondos ( $\mathrm{mi}$ llones de imágenes digitales en línea sobre todos los temas posibles -historia, deporte, naturaleza, moda, cine, música, viajes, ciencia, etc.-, y miles de fotógrafos representados en todo el mundo), como por su volumen de negocio (oficinas propias y agentes distribuidos en distintos países, prestando servicios a todo tipo de clientes: publicidad y marketing, revistas, periódicos, libros, cine, televisión, la Web).

Sin embargo, el elevado volumen de negocio, los avances en la desambiguación y en la riqueza de los metadatos y la elevada usabilidad de estas herramientas, contrasta con la escasa literatura sobre ellos (Codina et al., 2003), (Codina; Del-Valle-Palma, 2001), (Muñoz-Castaño, 2001). Sirva este análisis introductorio para contribuir a conocer un poco mejor esta parcela del mercado de la información digital, basándonos en los principales actores del sistema, con el fin de obtener el perfil y las características básicas que cualquier banco de imágenes comercial debe ofrecer a sus clientes y usuarios, con independencia de su tamaño (Pack, 2009), en cuestiones tales como la recuperación de imágenes, su visualización en pantalla y su descarga para diversos fines editoriales (Corbis, 2010; Getty Images, 2010; Reuters, 2010).

\section{Búsqueda de imágenes}

Como en muchos otros productos y servicios tanto gratuitos como de pago, el paso previo para el acceso a los bancos de imágenes pasa por el registro del usuario. Algunos de ellos permiten la realización de búsquedas sin registrarse previamente, siendo el registro obligatorio sólo para la descarga de archivos en alta resolución. Esto conlleva algunos inconvenientes, entre ellos la marca de agua en las imágenes en baja resolución, que no permitirá la realización de maquetaciones limpias, o la imposibilidad de visualizar la totalidad de las colecciones del banco de imágenes, con el consiguiente riesgo de elegir una fotografía cuyo uso no esté autorizado en nuestra zona geográfica.

Todo buen banco de imágenes debe ofrecer la posibilidad de cambiar el idioma de interrogación. Actualmente muchas de las webs identifican automáticamente mediante reconocimiento de IP desde qué país se conecta el usuario y presentan la información en el idioma correspondiente, ahorrando así el paso de selección de lengua. Sin embargo, esto no debe excluir la posibilidad de modificarlo, porque es frecuente que se produzcan diferencias en los resultados dependiendo del idioma empleado en la consulta.

Por lo que respecta a las búsquedas, el usuario debe tener a su disposición una serie de opciones que le ayuden a definir su consulta en función de la imagen que necesite, incluyendo la posibilidad de expandir/restringir los resultados tras una búsqueda específica/general. De la misma forma que sucede en motores de búsqueda convencionales, el del banco de imágenes debe permitir una búsqueda rápida que facilite la introducción de palabras clave en un cuadro de texto sencillo. Pero también debe contemplar la posibilidad de realizar una búsqueda avanzada donde, además de introducir las palabras clave, se puedan definir una serie de variables que limiten y adecuen los resultados de la consulta, como:

\footnotetext{
- tipo de licencia: royalty free -RF- o derechos protegidos $-\mathrm{DP}-$.

- tema o colección;

- tipo de imagen: fotografía, ilustración, vídeo;

- imágenes en color o blanco y negro;
} 
- orientación: vertical, horizontal, panorámica);

- restricciones o autorizaciones específicas de uso;

- fecha concreta o período cronológico;

- personas que aparecen en la fotografía: ninguna, una, dos, grupo, multitud;

- zona geográfica: continentes, zonas geopolíticas y zonas socioeconómicas;

- tipo de plano: general, entero, medio, medio-corto, primer plano, plano americano, perfil, etc.;

- ángulo o perspectiva: normal, picado, cenital, lateral, vista aérea;

- autor/fotógrafo.

Las opciones de ayuda y asistencia en las consultas repercuten en la mejora de la usabilidad del sitio y en la percepción que el usuario tiene del servicio

Las opciones de ayuda y asistencia en las consultas no sólo redundan en la mejora de la usabilidad del sitio, sino que repercuten positivamente en la percepción que el usuario tiene del servicio. En palabras de Klein, cofundador de Getty, "si tienes la fotografía adecuada para el usuario pero éste no puede localizarla fácilmente, no tienes la fotografía adecuada". En este sentido, opciones como autocompletar palabras a medida que se introducen los primeros caracteres del término a buscar, mostrarán un listado de palabras clave sugeridas que ayudarán a contextualizar o a acotar la búsqueda en caso de ser relevantes (tecleando "juegos" aparecen opciones como "juegos de invierno", "juegos de verano", "juegos olímpicos", etc.).

No menos importante, y unas de las más poderosas actuaciones para evitar la ambigüedad terminológica, son las aclaraciones semánticas (Ojala, 2009). Ante la introducción de una palabra polisémica el sistema debe facilitar un sencillo instrumento de aclaración de la consulta con una serie de opciones distintivas previas a la presentación en pantalla de los resultados. Así, y como se puede apreciar en las figuras 1 y 2 , ante la consulta "naranja", el sistema permitirá distinguir entre "naranja (fruta)" y "naranja (color)"; en el caso de "león", el sistema tratará de desambiguar con las opciones "león (animal)" y “León (topónimo)".

Emulando opciones avanzadas disponibles en otros sistemas de uso cotidiano, como la compra en línea, los bancos de imágenes deben permitir la realización de consultas a par-

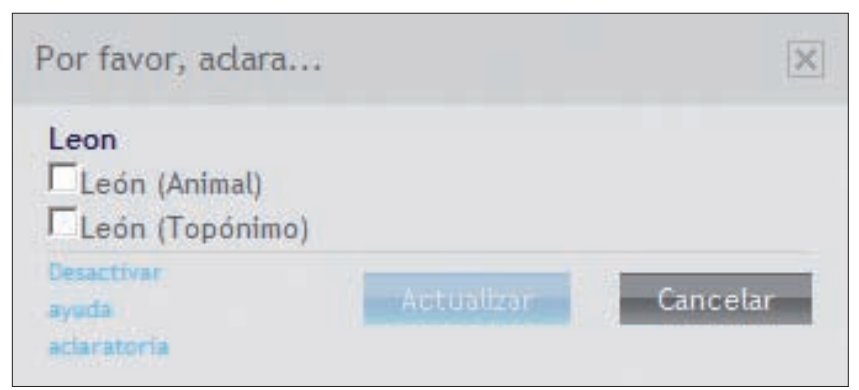

Figura 1. Pantalla flotante de desambiguación terminológica. Fuente: Corbis

\section{Por favor, aclara tu búsqueda}

$$
\begin{aligned}
& \text { "naranja" } \\
& \square \text { Naranja (Color) }
\end{aligned}
$$

Naranja (Fruta cítrica)

Figura 2. Opciones de desambiguación terminológica. Fuente: Getty

tir de imágenes relacionadas. Esta posibilidad consiste en que, una vez ejecutada la búsqueda y localizada la imagen, es posible obtener nuevas imágenes relacionadas con la seleccionada, bien por tratarse de la misma sesión fotográfica, coincidir los modelos o lugares, la composición, colores, el autor o por tener los mismos descriptores, entre otros.

Una vez realizada una búsqueda y accediendo a los detalles de la imagen, deben ser visibles las palabras clave asignadas. El usuario podrá ejecutar una nueva consulta seleccionando las que considere más adecuadas, con el fin de obtener nuevos resultados a partir de la redefinición de la búsqueda de acuerdo con los términos asignados a las fotografías. Esta opción es especialmente útil cuando el usuario no está familiarizado con el código terminológico empleado por la herramienta.

Un último aspecto relacionado con la búsqueda de imágenes es la selección y el almacenamiento de los resultados obtenidos mediante carpetas personalizadas (álbumes, lightboxes o mesas de luz, según la herramienta utilizada). EI sistema de recuperación debe permitir la recopilación de las imágenes seleccionadas en las distintas búsquedas, y la creación de colecciones personalizadas en línea a las que se podrá nombrar, añadir notas, mover imágenes de unas a otras, imprimir (como hoja de contactos fotográficos), enviar por correo electrónico a otros destinatarios (en forma de URL), compartirlas con otros usuarios (sólo consulta o con permisos para añadir o eliminar imágenes), y enviar directamente a la zona de descargas para su compra.

Además de todas estas opciones de ayuda, todos los archivos fotográficos en línea deben ofrecer un servicio de asistencia a la búsqueda de imágenes, ya sea por teléfono o por correo electrónico, dirigido y gestionado por profesionales de la información y la documentación, que permita al usuario solicitar el envío de selecciones de imágenes de acuerdo con unos criterios predefinidos. Este servicio adicional, de gran valor añadido, facilitará el trabajo de los clientes que por falta de tiempo en un determinado proyecto, o por poca experiencia en la localización de imágenes, necesiten una rápida respuesta.

\section{Visualización de resultados}

El segundo de los aspectos relevantes a tener en cuenta a la hora de diseñar o usar un banco de imágenes atañe a la visualización de los resultados en pantalla. En este caso, y como primer requisito de cualquier sistema de búsqueda, una vez ejecutada la consulta deberá mostrarse información acerca del número de imágenes recuperadas según los criterios especificados por el usuario.

Debido a la especial naturaleza de este tipo de objetos digitales, el sistema debe contar con instrumentos que permitan la personalización del número de imágenes disponibles 


\section{Opciones de visualización}

\section{Visualización \\ c.

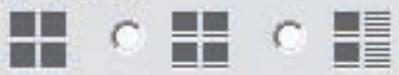

\section{Detalles de la miniatura \\ $\sqrt{\checkmark}$ Categoria $\quad \nabla$ Titulo y pie al poner el cursor \\ $\sqrt{\checkmark}$ Colección $\quad \nabla$ Fecha \\ 『 Número de imagen $\Gamma$ Créditos/Fotógrafo}

Autocompletar

Ayuda aclaratoria

(p. ej. Naranja: Color o Fruta)

\section{Aplicar Cancelar}

Figura 3. Pantalla de selección de información adicional para miniaturas. Fuente: Corbis

por pantalla (el número máximo oscila entre las 100 y 300 instantáneas). Asimismo, y muy relacionado con la característica anterior, se debe permitir elegir el tamaño de visualización de las miniaturas (thumbs). En ambos casos, estas preferencias se verán influidas por el nivel de conocimiento del usuario y de su destreza y rapidez visuales, así como por el tamaño de la pantalla que emplee para la visualización de resultados (no inferior a 21 pulgadas en el ámbito editorial profesional).

También es recomendable que el sistema de recuperación permita incluir información adicional en pantalla junto a la miniatura mediante opciones como: sin información (sólo la imagen), con información básica (código de imagen, tipo de licencia -DP/RF-, colección), con información completa (personalizando los campos que se mostrarán): número o código de imagen, tipo de licencia (DP/RF), colección, fotógrafo, pie de foto, fecha (figura 3).

La opción de vista previa debe activarse con el sencillo movimiento de pasar el ratón sobre la miniatura. La activación o desactivación será una de las preferencias del usuario. Como alternativa, al pinchar sobre la miniatura se abrirá en ventana nueva la previsualización de la imagen. En este caso, es recomendable desde el punto de vista de la usabilidad de la aplicación que se pueda navegar entre las vistas previas de las imágenes que preceden o suceden a la elegida sin necesidad de volver a pinchar sobre la siguiente miniatura.

Por lo que respecta a la ordenación de los resultados, estos deberían poder agruparse al menos por fechas (la más reciente primero), permitiendo la posibilidad de distinguir entre fecha de carga en el sistema y fecha de captura de la imagen; y por relevancia formal, en función de la aparición de los términos de búsqueda en la descripción.

Es preciso destacar que, con independencia del tipo de acuerdo o contrato que el usuario haya suscrito con el ban- co de imágenes, existen fotografías que aun siendo accesibles poseen unas condiciones especiales o restricciones relacionadas con su precio o con su licencia de uso. Estas excepciones, dado que son frecuentes, deben aparecer claramente identificadas (mediante un icono de rápida visualización o una nota destacada) en aquellas fotografías que presenten singularidades en cuanto a derechos de imagen o restricciones de uso o precio, con el fin de que el usuario pueda identificarlas rápida y fácilmente, para descartarlas o para leer detenidamente la información restrictiva antes de decidir acerca de su adquisición.

Finalmente, entre las opciones indispensables que se deben incluir a la hora de visualizar imágenes en pantalla se encuentra la de acceder al listado de palabras clave o descriptores asociados a la imagen. Como ya se ha indicado en el apartado anterior, esta información permitirá la redefinición de la consulta mediante la selección de aquellos términos que faciliten la obtención de nuevas fotografías.

\section{Descarga de imágenes}

El último de los apartados a tener en cuenta a la hora de gestionar o trabajar con un banco de imágenes es el de la descarga de fotografías procedentes de los pasos anteriores. Este procedimiento ha de ser sencillo (sin excesivas confirmaciones ni pasos intermedios), rápido (aunque siempre dependiendo del ancho de banda disponible) y amigable (intuitivo y fácil de manejar para usuarios inexpertos).

El formato de descarga habitual de archivos comerciales es compresión en JPEG y modo de color RGB. En cuanto al modo de descarga, el usuario debe poder elegir entre descarga directa a su equipo (generalmente se emplean archivos comprimidos en formato ZIP o similar cuando se descargan dos o más imágenes), el envío a su correo electrónico, o la descarga mediante FTP.

Se debe permitir la descarga en diferentes tamaños y resoluciones en función del uso que se vaya a dar a las imágenes:

- baja resolución: imágenes aptas para web;

- media resolución: permite maquetar con más calidad (presentación de proyectos) pero aún insuficiente para publicar con la calidad necesaria en papel;

- alta resolución: generalmente cuentan con un tamaño A4 y una resolución de 300 dpi;

- tamaños especiales: debe existir la posibilidad de solicitar imágenes en gran tamaño para proyectos determinados de gran formato, y con un plazo de respuesta inferior a 24-48 horas.

En todos los casos, independientemente del tamaño que se necesite, el banco de imágenes debe permitir descargas individuales o descargas en grupo (paquetes). En este último caso, no debería existir un límite de imágenes que obligara al cliente a fragmentar la descarga y repetir el proceso, aunque la mayor parte de las ofertas comerciales establecen un máximo de entre 20 y 30 instantáneas. Lo ideal es que sea el propio sistema el que divida la descarga automáticamente en diferentes paquetes de forma que el usuario sólo tenga que seleccionar cada uno de ellos evitando la molesta repetición de todo el proceso. 
En el caso de descarga por grupos o paquetes, el sistema debe ser sensible a:

- cancelar la descarga de imágenes que aunque hayan sido previamente seleccionadas, finalmente no se deseen utilizar o descargar;

- seleccionar el tamaño de cada imagen individualmente;

- permitir la adición de anotaciones para cada fotografía (como el proyecto o publicación en la que se va a usar), de forma que al consultar el histórico de descargas o recibir el informe de descargas pueda identificarse rápidamente el objetivo o la obra a la que se dirige cada imagen. Esta opción debe ser opcional puesto que puede afectar a la velocidad de descarga.

Los informes o históricos de descargas mencionados en el punto anterior facilitarán el control del gasto por parte del usuario, e identificar ágilmente imágenes que deban ser obtenidas de nuevo debido a extravíos, eliminaciones accidentales o por fallos durante el proceso.

\section{Conclusiones}

Los bancos de imágenes, y no sólo los de las empresas que dominan el mercado de la fotografía digital, se encuentran en la vanguardia de las herramientas de búsqueda de información. Quizá sea por su volumen de negocio anual, estimado por Piclet en más de 150.000 millones de euros para 2013, o por la especial idiosincrasia del material con el que trabajan, lo cierto es que sus sistemas de búsqueda, visualización y descarga de información son extraordinariamente versátiles desde el punto de vista profesional, y extremadamente útiles para sus clientes.

Son abanderados en la contribución a la denominada web semántica, gracias a la introducción de instrumentos cada vez más precisos a la hora de transformar la relevancia formal en relevancia semántica. Ello incluye la descripción del contenido de las fotografías, con un ingente trabajo taxonómico para lograr la desambiguación terminológica, pero también la incorporación de metadatos específicos que trascienden lo inmediatamente tangible, dando paso al ámbito de las sensaciones o de las ideas. Sirvan como muestra herramientas recientemente incorporadas a algunos motores como la localización por coordenadas GPS, la búsqueda de colores dominantes o las sugerencias ofrecidas mediante nubes de ideas. En la actualidad se trabaja en el reconocimiento automático de formas y rostros.

La imagen digital se enmarca dentro de un mercado rico en recursos pero también enormemente exigente y competitivo. Son cada vez más numerosas las iniciativas profesionales que tratan de ganar cuota de mercado diversificando y especializando oferta y tratando de asegurar la sostenibilidad del sistema, incluyendo remuneraciones justas para los profesionales de la fotografía. Todo este torrente tecnológico, terminológico y económico es caso de estudio en algunas de las más prestigiosas escuelas de negocio y debería serlo también para las escuelas de información y documentación, especialmente entre aquellos expertos vinculados con los sistemas de recuperación de información.

Resulta sorprendente encontrar más lecturas sobre este tipo de organizaciones en prensa económica que en revistas académicas o profesionales. Este análisis ha tratado de contribuir a la exploración sucinta de los sistemas empleados por estas instituciones y a la descripción de sus especificaciones fundamentales. Trabajos complementarios a éste podrían centrarse en la descripción de los principales programas disponibles para la creación de bancos de imágenes, algunos de ellos mencionados en el apartado introductorio, la situación española en el mercado global de la fotografía digital (agencias y software) o en profundizar en la descripción y clasificación de los bancos de imágenes, incluyendo los tipos de materiales, los metadatos avanzados y los aspectos legales que les afectan.

\section{Bibliografía}

Codina, Lluís; Del-Valle-Palma, María. "Bancos de imágenes y sonido y motores de indización en la www". Revista española de documentación científica, 2001, v. 24, n. 3, pp. 251-274.

Codina, Lluís; Del-Valle-Palma, María; Marcos, Mari-Carmen. "Arquitectura de la información y representación del conocimiento: el caso de los bancos de imágenes en la Web". En: VIII Jornadas españolas de documentación. Barcelona: Fesabid, 2003, pp. 321-342.

Corbis. Guía de sugerencias y palabras clave. Seattle: 2010. http://www.corbisimages.com/SearchTips/SearchTips_esES.pdf

FotoWeb. Oslo: Fotoware, 2011. http://www.fotoware.com

Getty Images. Guía de búsqueda. Seattle: 2010. http://imagery.gettyimages.com/pdf/webvision/search_ guide.es.pdf

Infradox. Amsterdam: Xpertise-ICT, 2011.

http://www.infradox.com

Levine, Robert. "Photo wars: a \$2 billion business gets rough". CNN Money.com, 2007, April.

http://money.cnn.com/magazines/business2/business2_ar chive/2007/04/01/8403372/index.htm

Muñoz-Castaño, Jesús E. "Bancos de imágenes: evaluación y análisis de los mecanismos de recuperación de imágenes". El profesional de la información, 2001, v. 10, n. 3, pp. 4-18. http://www.elprofesionaldelainformacion.com/contenidos/ 2001/marzo/1.pdf

Ojala, Marydee. "The winds of change". Online, 2009, March-April, p. 5

Orphea Studio. Paris: Algoba Systems, 2011. http://www.orphea.com/index_es.htm

Pack, Thomas. "How amateur photographers can make a buck". Information today, 2009, October, pp. 38-39.

Piclet. The Web's photography war, 2011.

http://www.piclet.com

Reuters. User guide. Nueva York: Thomson-Reuters, 2010. http://pictures.reuters.com/doc/RTR/Media/OtherMedia/ Reuters\%20Pictures\%20User\%20Guide\%201\%204.pdf 